\title{
Ride-sharing Service in Bangladesh: Contemporary States and Prospects
}

\author{
Saiful Islam ${ }^{1}$, Ekramul Huda ${ }^{2} \&$ Farjana Nasrin ${ }^{3}$ \\ ${ }^{1}$ Assistant Professor, Department of International Business, University of Dhaka, Bangladesh \\ ${ }^{2}$ Lecturer, Department of International Business, University of Dhaka, Bangladesh \\ ${ }^{3}$ Freelanch Researcher, MBA, Department of International Business, University of Dhaka, Bangladesh \\ Correspondence: Saiful Islam, Department of International Business, University of Dhaka, Bangladesh. E-mail: \\ saifulib@du.ac.bd
}

Received: May 24, 2019

Accepted: June 30, 2019

Online Published: August 5, 2019

doi:10.5539/ijbm.v14n9p65

URL: https://doi.org/10.5539/ijbm.v14n9p65

\begin{abstract}
This study aims to identify the current status and prospect of ride-sharing service in Bangladesh from the users' perspective. Data has been collected through a survey questionnaire from a sample of 164 respondents and analyzed using simple descriptive statistics. Findings show that ride-sharing services are emerging rapidly in Bangladesh as an alternative to traditional transportation because people prefer flexibility, convenience, time savings, and ease of use. The young generation is the top user of this service as they well equipped with the technologies required for this gig economy. Currently, Uber and Pathao, only two companies hold more than three-quarter of the market share because of their first mover advantage and availability in both car and motorbike segments. Further growth of this service is expected if major problems like concern over safety and security can overcome. Thus, this study would be useful for companies understanding users' perception and improving their service quality.
\end{abstract}

Keywords: Bangladesh, present condition, prospects, ride sharing service

\section{Introduction}

Ride-sharing service is an emerging mode of transport that positively contributes to economic, environmental, and social sustainability (Geisberger et al., 2009; Hansen et al., 2010). This service ensures efficient and convenient transportation through the use of smartphone technology which enrich the experience of personalized mobility in timely fashion. Consequently, app-based vehicle service system has increased dramatically over the past few years as a part of finding the nearest vehicle in a short time. Consumers are always in search of inexpensive ways to get around where an app makes the process smooth (Chen et al., 2011). Moreover, in the advent of telecommunication, consumers can easily track driver's location to pick them up, provide fares and positive feedback on their consumption through this mobile app used in ride-sharing services (Posen, 2015).

Nowadays ride-sharing service has become very popular in developed as well as in developing countries. Consequently, academic researchers, entrepreneurs, business persons, innovators, and policy-makers are showing greater interest in the nature and impacts of this ride-sharing service on economies. From a business perspective, this service can create more opportunities in terms of market share and social benefits. Moreover, ride-sharing companies are also benefited by new dimensions of service use and a new area of earning a profit (Belk, 2014). In addition to these, users also get benefits from ride-sharing service as a potential solution to the different problems of traditional transportation sectors like congestion relief, improved travel options (DeMaio, 2009).

Consequently, with the wave of other countries, some of the ride-sharing companies started their operations in Bangladesh like Uber, Pathao, Amarbike, Taxiwala, Garivara, Chalo, Sohoj ride, Obhai, Obon, and others. Within a short time, these companies launched innovative technology to make the mobility of the people more conveniently and flexible. Moreover, people are using the service frequently, which is further attracting newer companies to enter the market and making the competition intense. However, few such studies have been initiated in the least developed countries like Bangladesh to address the current situation future growth of ride-sharing services. Thus, the purpose of this study is to understand the present status and prospect of ride-sharing service in Bangladesh from the users' perspective. Therefore, this study considers the following 
objectives, first, to identify the present condition of ride-sharing service in Bangladesh, second, to determine the benefits and challenges of this service and third, to explore the prospects of ride-sharing service in Bangladesh.

The paper is organized into five different sections, including this introduction section. The remaining of the paper is as follows, the relevant literature and background regarding concepts, practices, prospects, and challenges of ride-sharing service and the existence of ride-sharing service in Bangladesh are presented in section 2. In section 3, the detailed methodology of this study is explained considering the research approach, data and sources, data collection methods, and data analysis techniques. Section 4 includes the result and relevant discussion of the significant findings. The conclusion and significant implications of the study are presented in the final section of the paper.

\section{Literature Review and Background}

\subsection{Concept of Ride-sharing Service}

Ride sharing is a time and facility oriented updated service using secure and convenient smartphone technology in real-time ride pooling where two groups of people as driver and passenger exists (Feeney, 2015; Geisberger et al., 2009). This service mostly involves efficient use of vehicles with a different mode of transportation, usually car and bike. In the era of digital sharing economy, ride sharing system extends with the availability of IoT (Internet of things), WoT (Web of Things) and smartphone technology to provide an opportunity for easy and flexible communication system for both riders and users (Chan \& Shaheen, 2012; Farin et al., 2016). Consequently, transportation network companies can make a significant change in this industry through the use of updated technology to address the present demand of new generation like reduced travel time, travel cost and traffic congestion (Bicocchi \& Mamei, 2014).

\subsection{Ride-sharing Service in Different Countries}

Recently, Uber in San Francisco, California has introduced as a solution to the present traffic situation and customer satisfaction which is backed by three generations of ride-sharing methods evolved over five decades (DeMaio, 2009). According to the author, the scenario of the present and future bike sharing service was revealed through the first generation at Amsterdam in 1965 with limited facilities and scope. Then the second generation at Copenhagen, Denmark in 1991 with some technological improvements; and the third generation at different locations around the world like England, France, Taiwan, South Korea, China, Chile, Brazil, New Zealand, and the United States in 1996 by updating the service quality and facilities. Moreover, Chan and Shaheen (2012) in their study categorized the evolution of North American ride sharing into five phases from 1942 to present based on a premium group of the society, energy crisis, institutionalization, reliability and advent of technology.

Furthermore, the use of ride-sharing service is rapidly expanded in different cities in Europe, U.S.A, Canada, Denmark, England, North America (Feeney, 2015). In the wave of the growing gig economy, development of ride-sharing services like Lyft, Uber, and Sidecar brought enormous competition in the industry in those locations (Wallsten, 2015). In this regard, using the demand pattern of the different user's group, Agatz (2011), in his study, showed how to predict the demand and competition of ride-sharing services in a meaningful way. Besides, Joseph et al. (2006) in their study addressed that creative ride sharing transport service make a tremendous positive impact in the life of city dwellers as well as for the society that also requires the cooperation of the companies and government. Moreover, ride-sharing service need to comply with the same regulations and standards set by the government for the taxis in different cities regarding price and safety (Midgley, 2011).

\subsection{Prospects and Challenges of Ride-sharing Service}

In his study, DeMaio (2009) identified that the future of ride Sharing service would be more efficient with the use of updated GPS tracking system, distribution of vehicles to everywhere in a country and a new business model. The near future of this service can be predictable as the traffic congestion is increasing because of more busy people wants to travel, and the world becomes conscious about environmental sustainability. However, Bicocchi and Mamei (2014) expressed that for long term success, every ride-sharing company needs to target consumers with more diversified user-friendly offers by anticipating demand. Moreover, this is a big challenge to deal with customers as several companies trying to serve the customers more efficient and flexible transportation system for congestion. Not only this competition but also different reasons and unexpected incidents make the ride-sharing service questionable (Kamau et al., 2016). Security still one of the primary concern among the users, especially the women passengers.

\subsection{Ride-sharing Service in Bangladesh}

The concept of ride-sharing service is aged; however, the extension of this service gained much popularity 
recently in emerging economies like Bangladesh (Kamau et al., 2016). Besides, the concept of ride-sharing in Bangladesh differs significantly with that of many other developed countries like the USA and UK. While it refers to the concept to share a ride with other two or more passenger to reach the same destination in developed countries, in Bangladesh, the concept take a new dimension as to search a ride with the smartphone apps and internet connection by selecting the places of destination. Moreover, the infrastructure, road networks, and communication system of Dhaka are not fully matched with that of other cities of developed countries (Chowdhury et al., 2016).

Additionally, Andaleeb, Haq, and Ahmed (2007) in their study identified that the citizen of Dhaka faces problems of not having a personal car where quality public transport facilities is also very fragile. However, the current situation of transportation and communication system in Bangladesh is improving with the technological enhancement, and the transportation market is expanding with different forms of ride-sharing service (Teubner \& Flath, 2015). Kumar, Jafarinaimi and Bin Morshed (2018) in their study discussed descriptively the existing transportation situation and Uber facility in Bangladesh using theory of justice and found that this service can create a positive impact on mobility and sharing economy. The introduction of Uber has created massive popularity of ride-sharing service among the young generation as well as some middle-aged people in Bangladesh. The main reason behind this popularity is the demand for flexible movement of the busy people in Bangladesh.

However, the previous studies regarding ride-sharing services discussed in the above sections focused mainly on different cities of developed countries rather than those of emerging economies. Thus, there is still a gap in the knowledge about the background, benefits, challenges, and prospect of ride-sharing service in emerging economies like Bangladesh, where ride-sharing service is evolving recently. A rigorous examination in this regard is essential for the people involved in this gig economy to know the present status and prospect of ride-sharing service in Bangladesh and develop their strategies accordingly. So far, in the concern of the researchers, there is no such previous study regarding the present status and prospect of ride-sharing service in Bangladesh. Thus, research concerning this issue would be more useful in the future.

\section{Methodology of the Study}

This study considers the perception of different participants in this industry to understand the present status and prospect of ride-sharing service in Bangladesh. Moreover, this study adopts a qualitative approach to examination with descriptive analysis. A qualitative approach often takes a descriptive and non-numerical method that explains a real-life setting more meaningfully. Moreover, the qualitative approach collects and analyzes information to understand the phenomenon, meaning, truth, reality, and conceptions in social science researches (Hossain, Siddique \& Islam, 2015). Authors also mentioned that, though the qualitative approach has few shortcomings like a time consuming, weaker forms of measurement, lower samples, reliability, and transparency, it provides greater flexibility and higher validity. Such validity can express through reviewing previous studies and information collected from respondents through a questionnaire survey.

In this regard, a survey questionnaire has been developed to identify users' perception regarding the present status and prospect of ride-sharing service in Bangladesh. Surveys are primarily suitable in explaining the features of a large population. Moreover, considering the same questions to all respondents with set of standardized stimuli, the survey generates reliability (Hossain et al., 2015). Thus, in this study, a survey questionnaire consists of eighteen questions regarding their demographic profiles and experiences of ride-sharing are distributed among potential respondents. Using a convenience sampling method, the survey questionnaire sent to around 200 respondents, where 164 returned useable with a response rate of $82 \%$. In addition to this, data are collected by sending the questionnaire through online medium during two months of the study period from January 2019 to February 2019.

Furthermore, the data collected has been analyzed using simple descriptive statistics. Descriptive statistics consists of different types of statistical analysis central to describing, summarizing, and explaining group of data to understand the key features easily (Christensen, Johnson \& Turner, 2015). Authors also mention that descriptive statistics summarize the key numerical characteristics of the data set through frequency distributions, percent, averages, graphs and charts, and relevant tables and figures. Other descriptive statistics include the measures of central tendency, measures of dispersion, and measures of relationship between variables and so on. Thus, users' perceptions regarding the present status and prospect of ride-sharing service in Bangladesh are analyzed based on frequency distributions, percent, averages, different charts, and graphs. A descriptive statistical analysis is a useful way to explore a social phenomenon and to create the groundwork for future research with more sophisticated statistical analysis. 


\section{Results and Discussions}

\subsection{Demographic Profile}

The table 1A in the appendix shows the demographic profile of the respondents. The respondent group consists of $56 \%$ male and $44 \%$ female. This almost equal representation of both genders is essential in the study of ride-sharing service in Bangladesh because, in recent times, both men and women of a young age are using this service frequently. Moreover, majority of the respondents (68\%) are students followed by business $(20 \%)$, services $(7 \%)$ and others $(5 \%)$. The occupation of the respondents also matched with the other demographic elements of the respondents. The student group is the primary user of ride-sharing services in Bangladesh as they enabled with the resources required in this service and actively seek low-cost transportation.

Moreover, the age distribution of the respondents also shows a similar trend. Around $42 \%$ of the total respondents belong to the age group of 23-27 years, followed by $38 \%$ of the respondents in the age group of 28-32 years. There are less than $4 \%$ of respondents aged above 37 years. Thus, this age distribution implies the suitability of ride-sharing services for the young generation. The young people aged between 20 to 35 years usually have a smartphone with internet connection required for ride-sharing service and actively seek quick transportation with the lowest possible cost. On the contrary, people aged more than 40 years are either well off to afford their ride or not technologically advanced, which reasoned for their minimum presence in the respondent group.

\subsection{Current Status of Ride-Sharing Services in Bangladesh}

Figure 1 shows the experience of ride-sharing service of the respondents. Around four-fifths of the respondent cohort had experienced a ride-sharing service in the past while only one-fifth of them never use any of the ride-sharing services in Bangladesh. This finding is very usual as people show interest in ride-sharing service based on different reasons and preferences even if they all have the same access to the service. Participants in this service sector may articulate marketing strategies to attract more of these potential consumers and increase the pie for higher revenue. Moreover, based on comfort, flexibility, and convenience, people vary on the selection of transportation mode while they frequently experience rideshare. Figure 2 shows that around $37 \%$ of respondents prefer a car only, while $33 \%$ of respondents prefer motorbike only. There are also $27 \%$ of respondents who are indifferent between these two modes based on their situation and convenience.

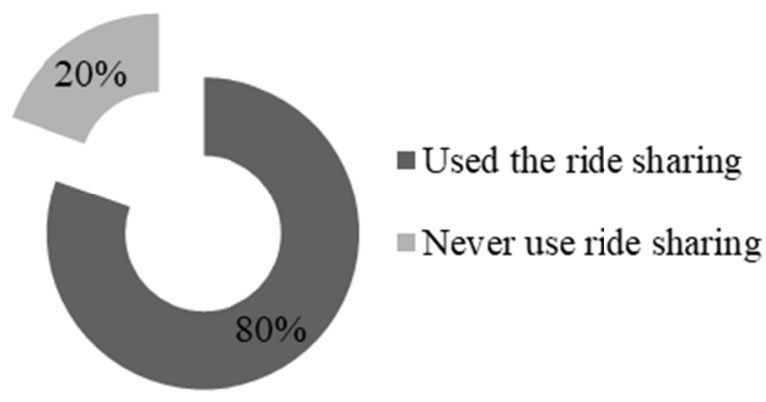

Figure 1. Experience of ride-sharing services

Source: Based on survey data, 2019.

In addition to this, figure 3 shows the most preferred service providers in the ride-sharing business of Bangladesh. Though this percentage does not classify the different modes of transportation, it reflects a rough estimation of current market shares of the ride-sharing service providers. Several service providers already entered in the market like Uber, Pathao, Amarbike, Taxiwala, Garivara, Chalo, Sohoj ride, Obhai, Obon, and others. Among which few offers both car and motorbike. Figure 3 shows that consumers prefer mostly Uber (40\%) and Pathao (38\%) among all ride-sharing services though there were free to select more than one service provider. All other ride-sharing services hold an insignificant portion of the market share (around 12\%) currently. The reasons behind this high preference of Uber and Pathao are first mover advantage and presence in both modes of transportation. Uber is the pioneer of car ride-share service in Bangladesh while Pathao is in motorbike ride share. 


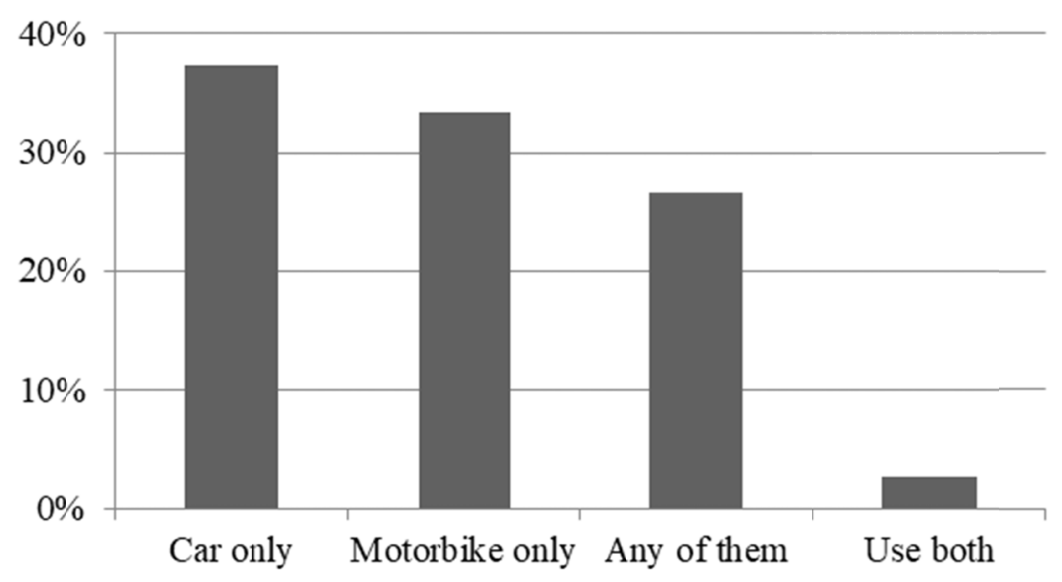

Figure 2. Preferred transportation mode

Source: Based on survey data, 2019.

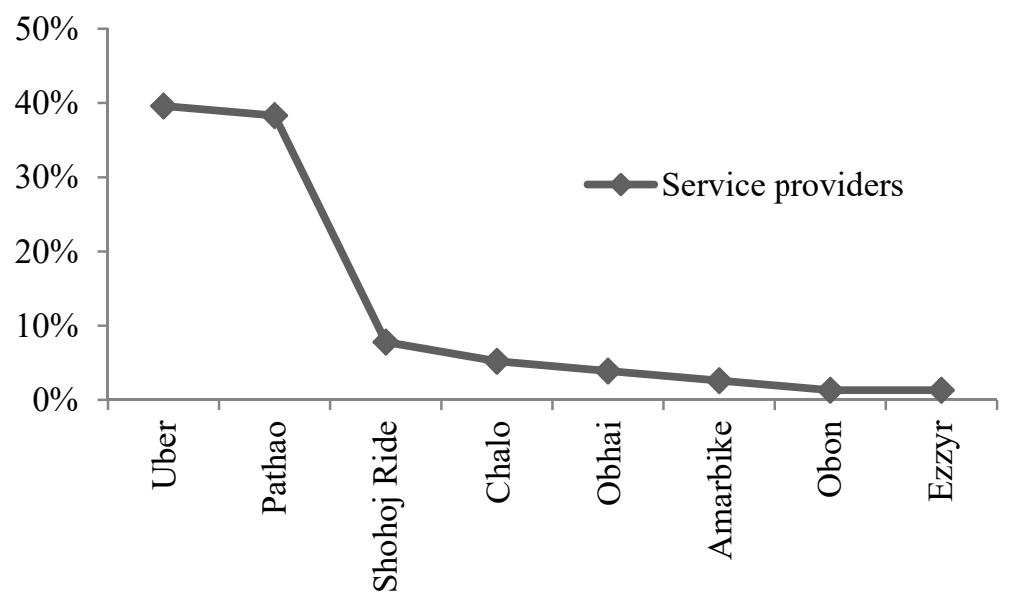

Figure 3. Preferred service provider

Source: Based on survey data, 2019.

However, respondents also reflect the reasons why they do not prefer ride-sharing service. Around $20 \%$ of respondents never feel interested in using any of the ride-sharing services, while another certain percentage had experienced the ride-sharing but not interested in selecting this as their primary mode of transportation. Respondents were free to select more than one option, which reflects their situation most. Figure 4 shows that most of the people (26\%) avoid ride-sharing service for the concern over security. Though ride-sharing service operates through GPS tracking and all detailed information is recorded in real time, people often felt insecure for various reasons, especially women in the night time. People also ignore the ride-sharing service equally (21\%) when they find a physical meeting point as a challenge and reluctant to provide detailed real-time information. Few others also constrained by technological requirement and find using an app for transportation quite tricky. 


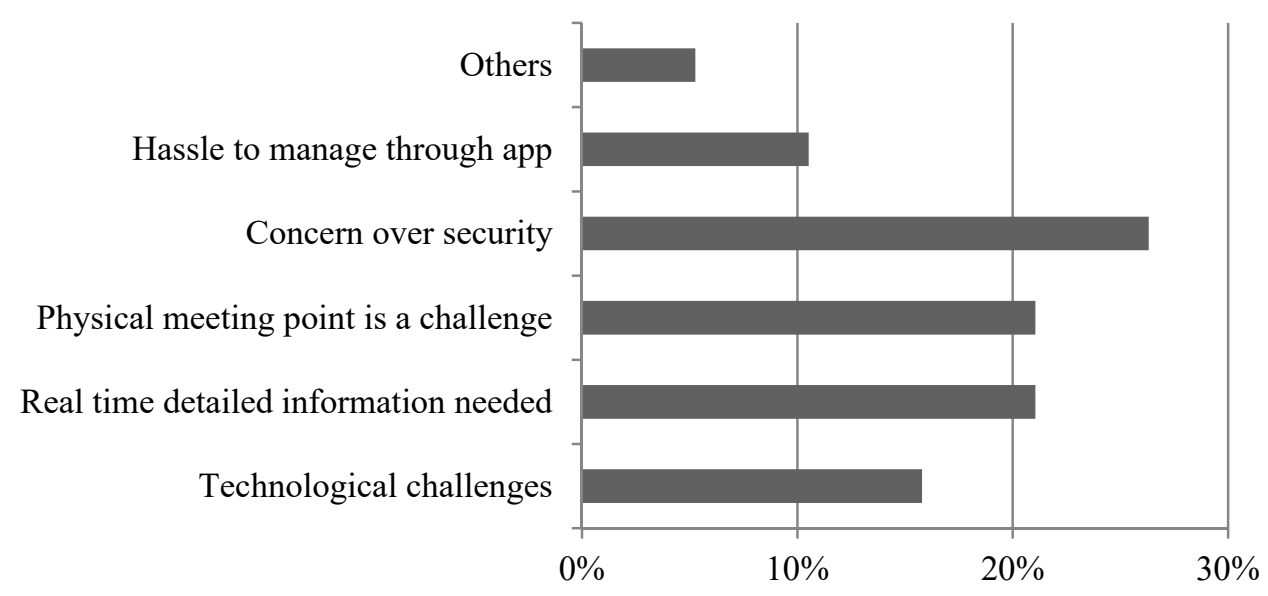

Figure 4. Reasons behind ignorance of ride-sharing services

Source: Based on survey data, 2019.

Moreover, those who use the ride-sharing service frequently are asked to determine their average expenses on a personal trip. Figure 5 shows that on average most of the people (53\%) pay up to Tk. 150 followed by $36 \%$ of people pay an amount of Tk. 150 - Tk. 300. Only $11 \%$ of the respondents pay an amount higher than Tk. 300 per trip. To some extent, these expense classifications depict that ride-sharing service offers convenience and flexibility at a higher expense. The average expense has a more significant impact on consumption decision and if not carefully designed, may lead to lower than expected growth of ride-sharing service in future.

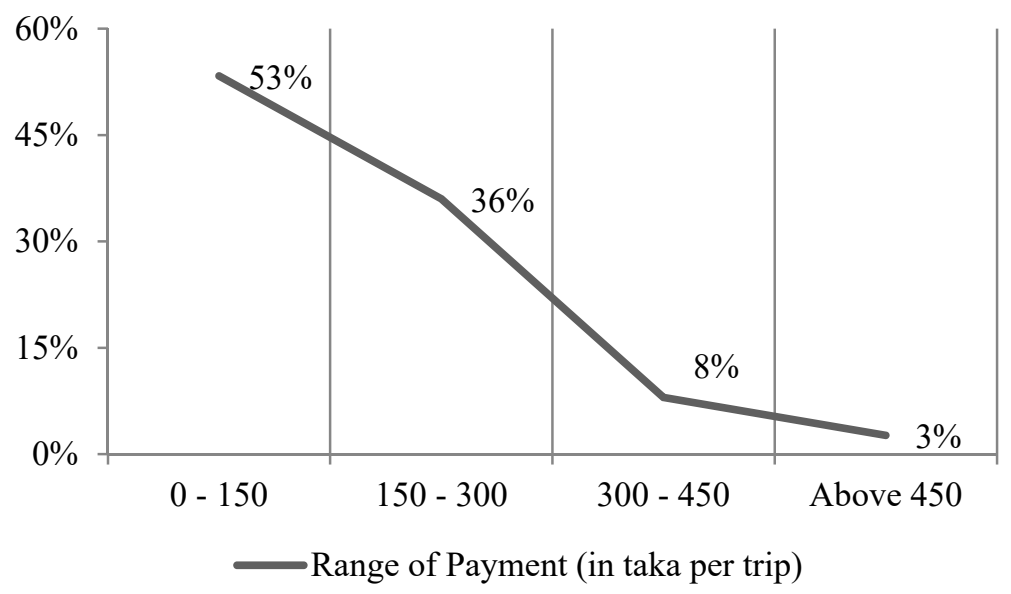

Figure 5. Range of average payment per trip

Source: Based on survey data, 2019. 


\subsection{Comparison of Ride-sharing Service with Traditional Modes of Transportation}

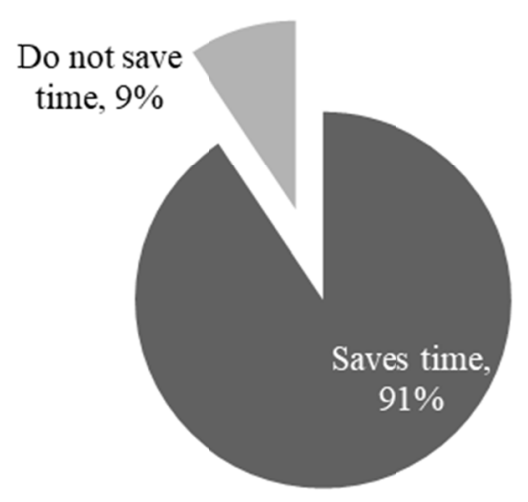

Figure 6. Preference of ride-sharing services on time savings

Source: Based on survey data, 2019.

In addition to determining the current status of ride-sharing service in Bangladesh, respondents are asked to compare this service with traditional transportation service of the city. Comparison is made in the context of payments, flexibility, convenience, time consumption, and ease of use. Figure 6 shows the users' perception regarding time consumption of ride-sharing service and traditional transportations. Majority of the respondents (91\%) perceive that ride-sharing service save time compares to the traditional mode of transportations. Rest of the respondents, however, prefer the traditional one or indifferent between two services. Thus, the prospect of the ride-sharing business is very high for the participants if they can make the service available to more potential consumers.

Moreover, figure 7 shows the comparison of ride-sharing service with traditional transportation on two important criterion- conveniences \& flexibility and expenses of the services. Responses of both criteria are classified as more preferred, less preferred, and depends on the situation. While the majority of the respondents (91\%) preferred ride-sharing service as more convenient and flexible than the traditional one, the rest assume it either less convenient and less flexible or indifferent. On the contrary, based on the expenses of the services, an almost equal number of people contradict with each other regarding the preference of ride-sharing service. While $47 \%$ of the respondents preferred ride-sharing service, $41 \%$ opposed to that. The prospect of ride-sharing service is considerably well as the majority of the people perceive these as a convenient and flexible mode of transportation. However, expenses of the service might be a significant obstacle to the growth of this service.

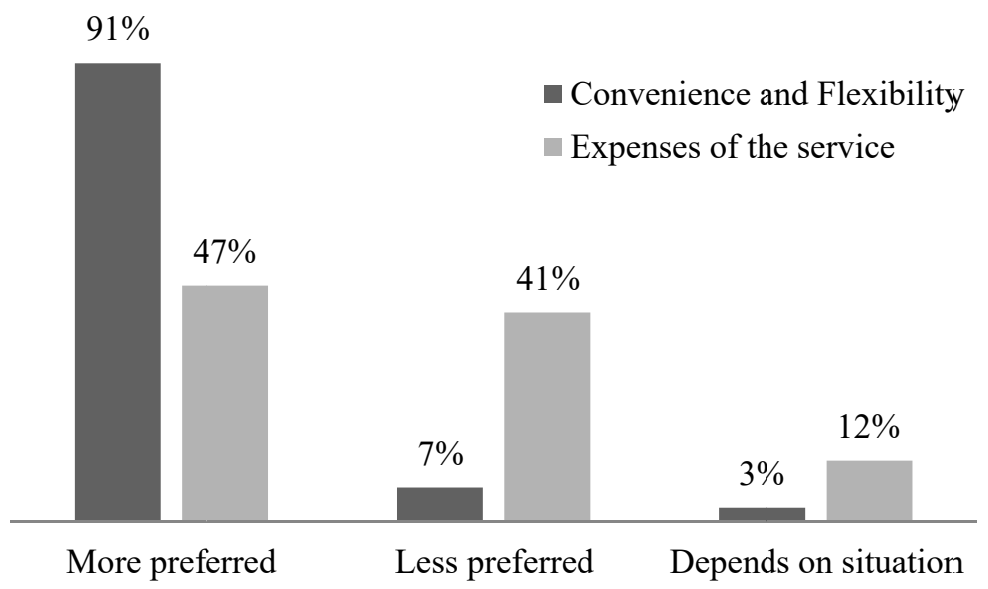

Figure 7. Preference of ride-sharing services on conveniences \& flexibility and expenses Source: Based on survey data, 2019. 


\subsection{The Future Prospects and Challenges of Ride-sharing Service}

Respondents are asked to express their intention to use the ride-sharing service with reasons. Figure 8 shows the frequency of the different reasons that respondents mentioned when they showed their intention to use ride-sharing service in the future. They mention the ease of use, flexibility, convenient, no bargaining of fare, comfort, and time savings, cheaper, fast, easy to manage, and less hassle as different reasons for choosing rise-sharing service. Respondents mention more than one reason as it is an open-ended question. The most common reason is the convenience, followed by reasonable fare, digital dealings, and availability. Other significant reasons for choosing ride-sharing service are the comfort and relax, followed by ease of manage, user-friendly and flexible, time-saving. Thus, people would choose ride-sharing service instead of traditional transportation in future if this service can be offered conveniently, at reasonable fare, flexible, and available in a timely fashion.

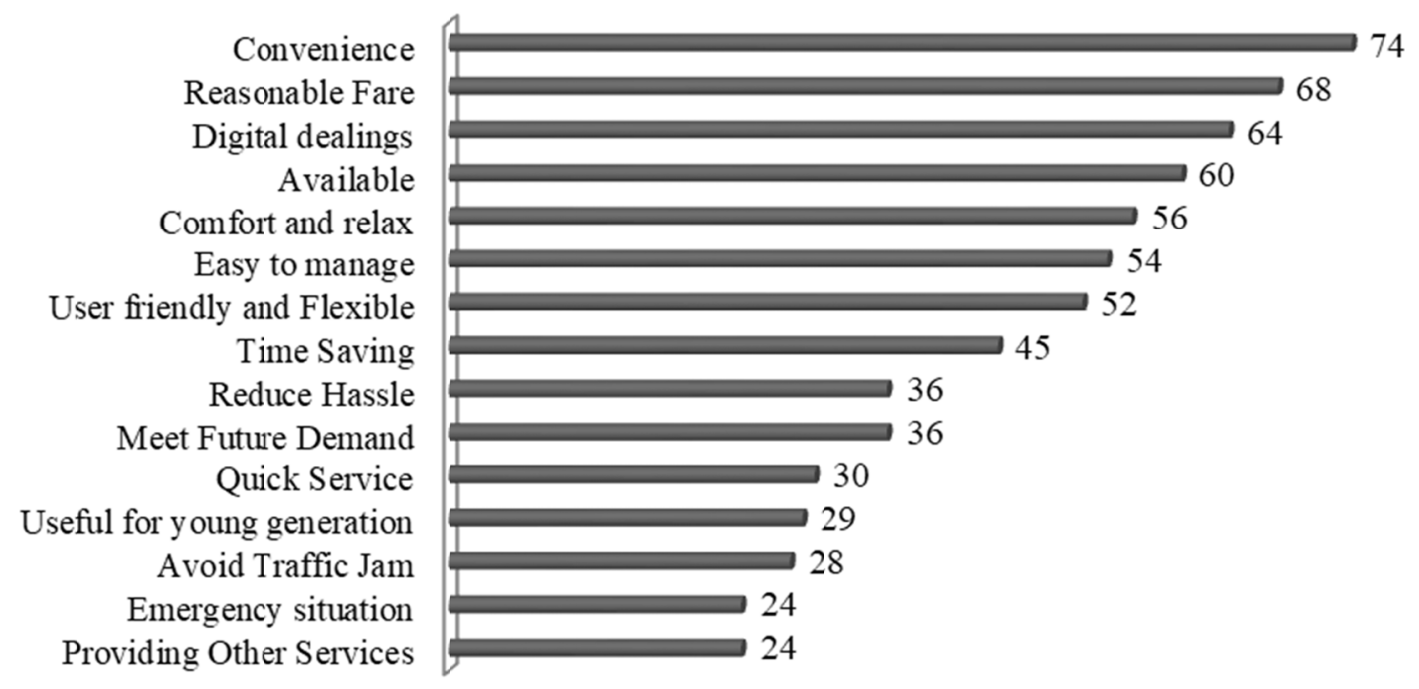

Figure 8. Reasons of choosing ride-sharing services in future

Source: Based on survey data, 2019.

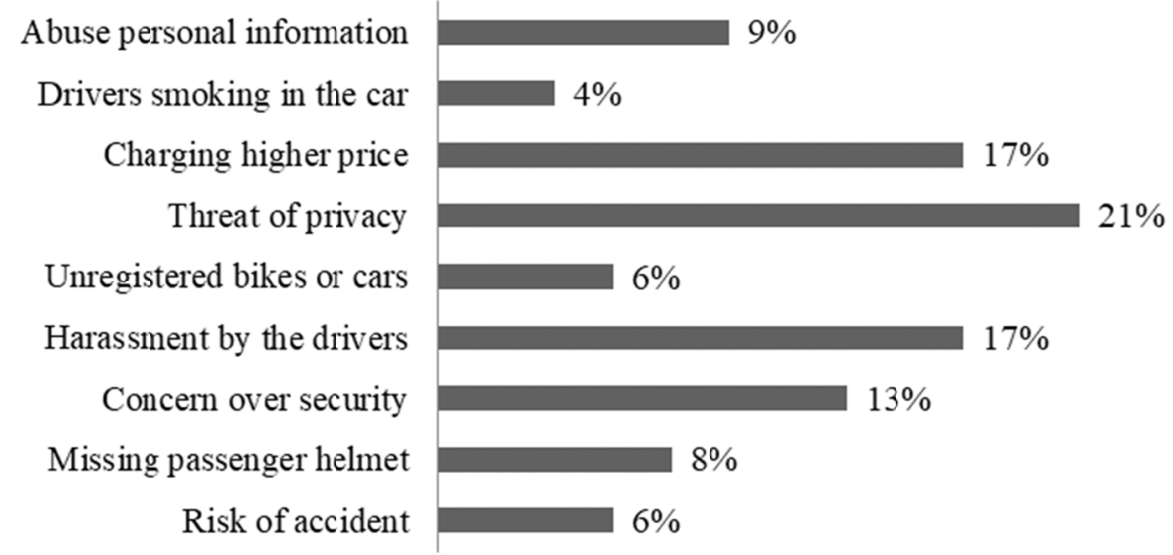

Figure 9. Problem faced in ride-sharing services

Source: Based on survey data, 2019.

Finally, respondents are also asked about the problem they face in ride-sharing service. Understanding these problems is essential to apprehend the current gap and prospect of this service in Bangladesh. Figure 9 shows one of the most significant issues of this service is the safety and security of the users. Respondents identified the 
threat of privacy (21\%), harassment by the drivers (17\%) especially for the women riding alone, and concern over security $(13 \%)$ as the most problematic issue over ride-sharing service which is all connected to safety and security of the passengers. Moreover, respondents also identified abuse of personal information (9\%), missing passenger helmet $(8 \%)$ and risk of accident $(6 \%)$ as the problems of this service. Only $17 \%$ of the respondents show concern over charging higher prices. Therefore, service providers should account these findings into their strategies to make the ride-sharing service safer and secured to the consumers. Otherwise, such a potential service sector may discard soon despite its colossal potentiality.

\section{Conclusion}

This study is aimed to identify the present status and prospect of ride-sharing service in Bangladesh from the users' perspective. In the context of Bangladesh, this research is one of the first of its kind that focused on three specific research objectives- identifying the present condition, exploring the benefits and challenges, and determining the prospects of ride-sharing service in the country. This study implements a qualitative method of inquiry where data is collected through a survey questionnaire using convenience sampling and is analyzed through descriptive statistics. Findings show that ride-sharing service is emerging rapidly in Bangladesh as an alternative to traditional transportation as people are interested in fastest and flexible commuting with low cost. In this regard, most consumers can afford a ride within Tk. 150, however sometimes which goes beyond Tk. 300 . The young generation, mostly the students, are the top user of this service as they are well equipped with the technologies required for this gig economy.

In addition to this, still, there is a segment in the population who did not use ride-sharing service ever or not interested in experiencing it in the future. The existing and future service providers may turn this segment into potential customers if they can solve the problems perceived by the consumers. Consumers show concern over safety and security issues of this service. However, a large group of users preferred ride-sharing service over traditional transportation in terms of payments, flexibility, convenience, time consumption, and ease of use. They showed interest to use these services in the future because of ease of use, flexibility, convenience, no bargaining of fare, comfort and time savings, cheaper, and less hassle. Currently, Uber and Pathao altogether hold more than three-quarter of the market share, and the users frequently prefer them because of their presence in both modes of transportation and first mover advantage.

Consequently, this study is useful for the existing and future service providers of this gig economy. It would help the companies to understand their customers' choices and perception of the services. Thus, companies need to articulate the findings into their strategies to create more market presence and to enhance business growth through customer satisfaction. However, this study is not beyond its limitations. This is a perception based study where a limited number of convenience samples are considered to determine the present status and prospect of ride-sharing service in Bangladesh. As this is exploratory research in this field, more conclusive research can be initiated in the future. Further studies can be initiated to determine consumers' attitude toward ride-sharing service, to measure consumers' satisfaction of the ride-sharing service, to compare the ride-sharing service with traditional transportation modes and so on. Future studies can also be taken place to evaluate this gig economy from the supply sides- how service providers perceive this economy as a profession. Furthermore, similar studies can be initiated in the other potential service sectors of the gig economy.

\section{References}

Agatz, N., Erera, A. L., Savelsbergh, M. W., \& Wang, X. (2011). Dynamic ride-sharing: A simulation study in metro Atlanta. Procedia-Social and Behavioral Sciences, 17, 532-550. https://doi.org/10.1016/j.sbspro.2011.04.530

Andaleeb, S. S., Haq, M., \& Ahmed, R. I. (2007). Reforming innercity bus transportation in a developing country: A passenger-driven model. Journal of Public Transportation, 10(1), 1-26. https://doi.org/10.5038/2375-0901.10.1.1

Belk, R. (2014). You are what you can access: Sharing and collaborative consumption online. Journal of Business Research, 67(8), 1595-1600. https://doi.org/10.1016/j.jbusres.2013.10.001

Bicocchi, N., \& Mamei, M. (2014). Investigating ride sharing opportunities through mobility data analysis. Pervasive and Mobile Computing, 14, 83-94. https://doi.org/10.1016/j.pmcj.2014.05.010

Chan, N. D., \& Shaheen, S. A. (2012). Ridesharing in North America: Past, present, and future. Transport Reviews, 32(1), 93-112. https://doi.org/10.1080/01441647.2011.621557

Chen, C. M., Shallcross, D., Shih, Y. C., Wu, Y. C., Kuo, S. P., Hsi, Y. Y., Holderby, Y., \& Chou, W. (2011). Smart ride share with flexible route matching. In Advanced Communication Technology (ICACT), 2011, 
13th International Conference on (pp. 1506-1510). IEEE.

Chowdhury, A., Jamal, A., Alam, R., \& Palit, R. (2016). Campus Ride: An Environment-Friendly Ride Sharing Platform for Academic Institutions. In Computer and Information Technology (CIT), 2016 IEEE International Conference on (pp. 120-124). IEEE. https://doi.org/10.1109/CIT.2016.110

Christensen, L. B., Johnson, R. B., \& Turner, L. A. (2015). Research methods, design, and analysis (12th ed.). Boston, MA: Pearson.

DeMaio, P. (2009). Bike-sharing: History, impacts, models of provision, and future. Journal of public transportation, 12(4), 3. https://doi.org/10.5038/2375-0901.12.4.3

Farin, N. J., Rimon, M. N. A. A., Momen, S., Uddin, M. S., \& Mansoor, N. (2016). A framework for dynamic vehicle pooling and ride-sharing system. In Computational Intelligence (IWCI), International Workshop on (pp. 204-208). IEEE. https://doi.org/10.1109/IWCI.2016.7860366

Feeney, M. (2015). Is ridesharing safe? http://www.memphistn.gov/Portals/0/pdf_forms/CATO.pdf,16.1.2016

Geisberger, R., Luxen, D., Sanders, P., Neubauer, S., \& Volker, L. (2010). Fast detour computation for ride sharing. In Proceedings of the 10th Workshop on Algorithmic Approaches for Transportation Modeling, Optimization, and Systems (ATMOS 2010), OpenAccess Series in Informatics (OASIcs) (Vol. 14, pp. 88-99).

Hansen, E. G., Gomm, M. L., Bullinger, A. C., \& Moslein, K. M. (2010). A community-based toolkit for designing ride-sharing services: the case of a virtual network of ride access points in Germany. International Journal of Innovation and Sustainable Development, 5(1), 80-99. https://doi.org/10.1504/IJISD.2010.034559

Hossain, M. D. K., Siddique, P. K., \& Islam, S. (2015). Socio-Economic Analysis of Informal Business Activities: A Case Study on Central Business District Area of Dhaka City. Developing Country Studies, 5(7), 1-10

Joseph, A.D., Beresford, A.R., Iftode, L., Fuchs, S., Lamprecht, B., Kyamakya, K., de Gracia Santos, J., Nimesh, M., Pan, G., Bacon, J. \& Wu, Z. (2006). Intelligent transportation systems. IEEE Pervasive Computing, (4), 63-67. https://doi.org/10.1109/MPRV.2006.77

Kamau, J., Ahmed, A., Rebeiro-H, A., Kitaoka, H., Okajima, H., \& Ripon, Z. H. (2016). Demand responsive mobility as a service. In Systems, Man, and Cybernetics (SMC), 2016 IEEE International Conference on (pp. 1741-1746). IEEE. https://doi.org/10.1109/SMC.2016.7844489

Kumar, N., Nassim J., \& Bin Morshed, M. (2018). Uber in Bangladesh: The Tangled Web of Mobility and Justice. Proceedings of the ACM on Human-Computer Interaction 2 (November): 98. https://doi.org/10.1145/3274367

Midgley, P. (2011). Bicycle-sharing schemes: enhancing sustainable mobility in urban areas. United Nations, Department of Economic and Social Affairs, 8, 1-12.

Posen, H. A. (2015). Ridesharing in the sharing economy: Should regulators impose Uber regulations on Uber. Iowa L. Rev., 101, 405.

Teubner, T., \& Flath, C. M. (2015). The economics of multi-hop ride sharing. Business \& Information Systems Engineering, 57(5), 311-324. https://doi.org/10.1007/s12599-015-0396-y

Tracy, S. J. (2010). Qualitative quality: Eight "big-tent" criteria for excellent qualitative research. Qualitative inquiry, 16(10), 837-851.

Wallsten, S. (2015). The competitive effects of the sharing economy: how is Uber changing taxis. Technology Policy Institute, 22. 


\section{Appendix}

Table 1A. The demographic profile of the respondents

\begin{tabular}{lc}
\hline Particulars & Percentage \\
\hline Gender & \\
Male & $56 \%$ \\
Female & $44 \%$ \\
Age & \\
$18-22$ & $6 \%$ \\
$23-27$ & $42 \%$ \\
$28-32$ & $38 \%$ \\
$33-37$ & $10 \%$ \\
$38-42$ & $2 \%$ \\
$43-47$ & $2 \%$ \\
More than 47 & $0 \%$ \\
Occupation & \\
Service & $7 \%$ \\
Business & $20 \%$ \\
Student & $68 \%$ \\
Others & $5 \%$ \\
\hline
\end{tabular}

Source: Based on survey data, 2019.

\section{Copyrights}

Copyright for this article is retained by the author(s), with first publication rights granted to the journal.

This is an open-access article distributed under the terms and conditions of the Creative Commons Attribution license (http://creativecommons.org/licenses/by/4.0/). 